http://jmscr.igmpublication.org/home/

ISSN (e)-2347-176x ISSN (p) 2455-0450

crossref DOI: https://dx.doi.org/10.18535/jmscr/v7i9.06

Journal Of Medical Science And Clinical Research

\title{
Immediate outcomes of Acute Coronary Syndrome: A hospital-based prospective observational study in a tertiary care institute in West Bengal, India
}

\author{
Authors \\ Dr Suman Biswas, Dr Biswanath Sharma Sarkar², Dr Shuvankar Mukherjee, \\ Dr Nabanita Bhattacharyya ${ }^{4}$ \\ ${ }^{1}$ Independent Researcher, Dept. of Community Medicine, Calcutta National Medical College, Kolkata \\ ${ }^{2}$ Associate Professor, Dept. of General Medicine, Diamond Harbour Government Medical College \& \\ Hospital, West Bengal \\ ${ }^{3}$ Assistant Professor, Dept. of Community Medicine, Calcutta National Medical College, Kolkata \\ ${ }^{4}$ Professor \& Head of the dept. of Community Medicine, Calcutta National Medical College, Kolkata \\ *Corresponding Author \\ Dr Biswanath Sharma Sarkar
}

Associate Professor, Dept. of General Medicine, Diamond Harbour Government Medical College \&

Hospital, West Bengal, India

\begin{abstract}
Introduction: Death due to Cardiovascular morbidities is one of the biggest health burden in India as well as worldwide. It is important to know the factors that may influence the outcome of the patients with Acute Coronary Syndromes (ACS).

Methods: A total of 112 patients with diagnosed ACS admitted at the Department of Cardiology in a tertiary care institute in West Bengal, India were monitored from the time of admission to the discharge or outcome. They were measured for several anthropometric parameters like height, weight, body fat percentage, BMI, waist circumference etc. and various other biochemical and cardiovascular tests were done, and they were noted for the outcome in terms of recovery following discharge or death, for a maximum of 10 days post-ACS. The data were analyzed by SPSS 20 and Kaplan-Meier survival analysis was done.

Results: Most common ACS was found to be left anterior descending artery ST segment elevated myocardial infarction (STEMI) (68.7\%). Mortality observed during the 10-day observation period was $16.1 \%$. Mortality rate did not vary significantly with the type of ACS $(p=.899)$. Survival Analysis showed that there were significantly more chances of survival in the patients with percutaneous coronary intervention (PCI) in comparison with the patients who received only thrombolysis in the beginning of the time $(p=.019)$ and at the end of the observation period $(p=.037)$. The survival curves for patients based on BMI, waist circumference and body fat percentage did not vary significantly $(p>.05)$.

Conclusion: It could be concluded from the present study that survival after ACS significantly associated with PCI and not with obesity or overweight.

Keywords: acute coronary syndrome, percutaneous coronary intervention, body fat percentage, survival analysis.
\end{abstract}

\section{Introduction}

Even after years of research and cutting-edge advancement in medical interventions, cardiovascular diseases remain the major cause of death in recent years both in India and worldwide. About 18 million people die each year from 
cardiovascular diseases, an estimated $31 \%$ of all deaths worldwide. $^{(1)}$ India is no exception; mortality due to cardiovascular diseases in this country is alarming. ${ }^{(2,3)}$ Beside other risk factors, obesity is a major health burden globally ${ }^{(4)}$ because of their strong association with a high risk of diseases of the metabolic syndrome that includes diabetes mellitus, certain forms of cancer and above all cardiovascular diseases ${ }^{(5,6)}$. In clinical settings the obesity measured objectively with body mass index (BMI), waist circumference (abdominal adiposity), waist to hip ratio and body fat percentage etc. and they are divided into several groups according to predetermined cutoffs. $^{(6,7)}$ The diagnosis, treatment, and management of the different forms of Acute Coronary Syndromes (ACS), which include Unstable Angina (UA), persistent ST-segment Elevation Myocardial Infarction (STEMI) and Non-ST-segment Elevation Myocardial Infarction (NSTEMI) have been rapidly evolving in recent years. ${ }^{(8)}$ Some studies showed an inverse relationship between obesity and mortality in cardiovascular diseases (CVD) and outcomes of post-ACS patients..$^{(9,10)}$ One possible reason behind this is thought due to cardio protective substances like adiponectin, leptin, and resistin released by adipose tissue. ${ }^{(11-17)}$ Through extensive research, improvement and suggestions have been proposed, the east Indian population is not yet studied for the immediate in-hospital mortality post ACS patients according to their level of body fat percentage. Apart from the geographical location, the population differs in dietary, social, behavioral and other genetically determined parameters. ${ }^{(18)}$ The population also differs in several definitions of obesity thus contributing to the metabolic syndrome and the outcome of the heart diseases was warned to the medical society ${ }^{(19,20)}$ The first few days post ACS is very critical as various complication can happen in that time which can be life-threatening. If the caring medical team can predict the positive and negative outcomes based on the patient profile it will be an efficient way to prioritize the treatment and care modality. In this backdrop, a study was conducted with the objective to find out the association, if any, of mortality due to the acute coronary syndrome with the type of intervention and obesity in post ACS patients admitted in a tertiary care institute in West Bengal, India.

\section{Material and Methods}

This prospective observational study was conducted in the department of Cardiology in a tertiary care institute of West Bengal, India, during the period of May to June, 2018. The study was approved by the institutional ethics committee. Patients admitted in the department of Cardiology for thrombolytic therapy or Percutaneous Coronary Intervention (PCI) with the defined clinical diagnosis of the acute coronary syndrome (ACS) that included unstable angina (UA), ST-elevation myocardial infarction (STEMI) and non-ST elevation myocardial infarction were included in the study during this period. A total of 112 patients were enrolled in the study after obtaining their informed consent. According to guidelines the patients were either intervened with Percutaneous Coronary Intervention (PCI) or thrombolytic therapy. And the patients were followed up for the periods of the hospital stay for any complication. The standard hospital stay was usually 10 days due to high patient burden to the center. A pre-designed and pre-tested proforma was used to collect data pertaining to socio-demographic profile, and history regarding hypertension (HTN), smoking, dyslipidemia, chronic renal failure, diabetes mellitus, thyroid disorders (both hypo- and hyperthyroidism) and alcohol use. Anthropometric measurements namely weight in kilogram, height in centimeters, waist and hip measurements in centimeters, skin fold thickness of men at thigh, abdomen, and chest in millimeters and that of women at triceps, supra-iliac, and thigh in millimeters were recorded at the time of admission or as soon as the patients were stabilized. The body mass index (BMI), body density (BD) and body fat percentage (BF\%) were 
calculated by Quetelet's, ${ }^{(21)}$ Jackson Pollock's ${ }^{(22)}$ and Siri's ${ }^{(23,24)}$ formulae respectively. Systolic and Diastolic blood pressure and other physical parameters were recorded at the time of admission and periodically thereafter till discharge or occurrence of death. Time since onset of symptoms or chest pain in hours, any medications on which the patient was on at the time of admission were also recorded. All the admitted patients were investigated with 12 Lead ECG in the Department of Cardiology and other tests consisting of Fasting Blood Sugar, Serum Urea, Creatinine sodium Potassium, and lipid profile. Troponin-T was tested qualitatively using disposable kits and subsequently quantitatively along with serum creatinine kinase MB (CK-MB) and lactate dehydrogenase $(\mathrm{LDH})$ at the Department of Biochemistry. Either percutaneous coronary intervention (PCI) or thrombolytics was used as an intervention for reperfusion. Besides that, all the patients were given aspirin, clopidogrel, beta blocker, ACE Inhibitors, enoxaparin, a vasopressor (epinephrine) as per standard guidelines except the patients with contraindication or adverse effects that emerged during treatment. All the patients were observed for the period of 10 days of hospital stay and outcome was noted as either recovery or death during this period.

Box 1: Formulae used to deduce BMI and Body Fat Percentage.

A. Quetelet index: BMI $\left(\mathrm{kg} / \mathrm{m}^{2}\right)=\operatorname{mass}(\mathrm{kg}) /$ height $(\mathrm{m})^{2}$.

\section{B. Jackson and Pollock to determine body density:}

Men: $\mathrm{D}=1.1125025-0.0013125(\mathrm{x})+0.0000055\left(\mathrm{x}^{2}\right)-0.000244(\mathrm{y})$

Women: $\mathrm{D}=1.089733-0.0009245(\mathrm{x})+0.0000025\left(\mathrm{x}^{2}\right)-0.0000979(\mathrm{y})$

Where $\mathrm{x}=$ sum of triceps, chest, and subscapular skin folds (in $\mathrm{mm}$ ) for men, and the sum of triceps, supercilium, and abdominal skinfolds for women, and $y=$ age in years.

\section{B. Siri's Equation to calculate body fat percentage:}

Percentage Body Fat $=(495$ / Body Density $)-450$.

\section{Definitions}

\section{Acute Coronary Syndrome:}

"The term acute coronary syndrome (ACS) refers to any group of clinical symptoms compatible with acute myocardial ischemia and includes unstable angina (UA), non-ST-segment elevation myocardial infarction (NSTEMI), and ST-segment elevation myocardial infarction (STEMI)." (25 - 27)

\section{Obesity}

According to BMI as per WHO guidelines, below $18.5 \mathrm{~kg} / \mathrm{m} 2$ is underweight, 18.5 to $24.9 \mathrm{~kg} / \mathrm{m} 2$ is normal, more than $25 \mathrm{~kg} / \mathrm{m}^{2}$ overweight, 25 to $29.9 \mathrm{~kg} / \mathrm{m} 2$ is preoboese, more than $30 \mathrm{~kg} / \mathrm{m} 2$ is obesity and 30-39.9 kg/m2 (obese class I), 35$39.9 \mathrm{~kg} / \mathrm{m} 2$ (obese class II), $>40 \mathrm{~kg} / \mathrm{m} 2$ (obese class III) ${ }^{(28,29)}$

Obesity according to Body Fat Percentage. ${ }^{(30)}$

\begin{tabular}{|l|c|c|}
\hline Description & Women & Men \\
\hline Essential fat & $10-13 \%$ & $2-5 \%$ \\
\hline Athletes & $14-20 \%$ & $6-13 \%$ \\
\hline Fitness & $21-24 \%$ & $14-17 \%$ \\
\hline Average & $25-31 \%$ & $18-24 \%$ \\
\hline Obese & $32 \%+$ & $25 \%+$ \\
\hline
\end{tabular}

Statistical analysis: Data were analyzed using SPSS (Statistical Package for Social Sciences) Version 20.0 IBM Corporation, Armonk, NY, USA. Chi-square test was applied to compare 
non-parametric data. Kaplan-Meier method was used in survival analysis for the categorical data along with Log Rank, Breslow, and Tarone-Ware post-hoc tests. A $p$ value of $\leq .05$ was considered statistically significant.

\section{Results}

In the present study around 48\% (54/ 112) belong to 40-59-year age group and around $45 \%$ belong to age group 60-79-year age (51/ 112). Around $73 \%$ was male and $27 \%$ was female. (Table 1) Most common ACS was found to be LAD STEMI $(68.7 \%)$. (Table 2). Around $13 \%$ were nonSTEMI. (Table 2) Mortality observed during the 10-day observation period was $16.1 \%$ (18/112). Death most commonly occurred in STEMI [18.2\% (14/77)]. (Figure 1) However, the mortality rate did not vary significantly according to the type of ACS $(\mathrm{p}=.899)$.

Kaplan-Meier's Survival Analysis showed that there were significantly more chances of survival in the patients with percutaneous coronary intervention (PCI) in comparison with the patients who received only thrombolysis, in the initial period $(p=.019)$ and at the end of the observation period $(\mathrm{p}=.037)$. However, it was not significant in the midportion of the hospital stay $(\mathrm{p}=0.065)$. (Figure 2) The survival curves for patients with presence or absence of obesity based on BMI, waist circumference (abdominal obesity) and body fat percentage did not vary significantly $(\mathrm{p}>.05)$. (Figure 3, 4, 5)

Table 1: Age and sex wise distribution of the patients $(\mathrm{n}=112)$

\begin{tabular}{|l|c|c|}
\hline Age group (years) & Male & Female \\
\hline$<40(\mathrm{n}=3)$ & $2(66.7)$ & $1(33.3)$ \\
\hline $40-59(\mathrm{n}=54)$ & $37(68.5)$ & $17(31.5)$ \\
\hline $60-79(\mathrm{n}=51)$ & $40(78.4)$ & $11(21.6)$ \\
\hline 80 and above $(\mathrm{n}=4)$ & $3(75.0)$ & $1(25.0)$ \\
\hline Total & $82(73.2)$ & $30(26.8)$ \\
\hline
\end{tabular}

Table 2: Types of ACS

\begin{tabular}{|l|c|c|}
\hline Type of ACS & Frequency & Percent \\
\hline Unstable angina & 2 & 1.8 \\
\hline LAD STEMI & 77 & 68.7 \\
\hline RCA STEMI & 10 & 9.0 \\
\hline Non-STEMI & 15 & 13.4 \\
\hline Anteroseptal MI & 8 & 7.1 \\
\hline Total & 112 & 100 \\
\hline
\end{tabular}

*LAD =Left Anterior Descending; RCA = Right Coronary Artery; STEMI= ST Elevation Myocardial Infarction.

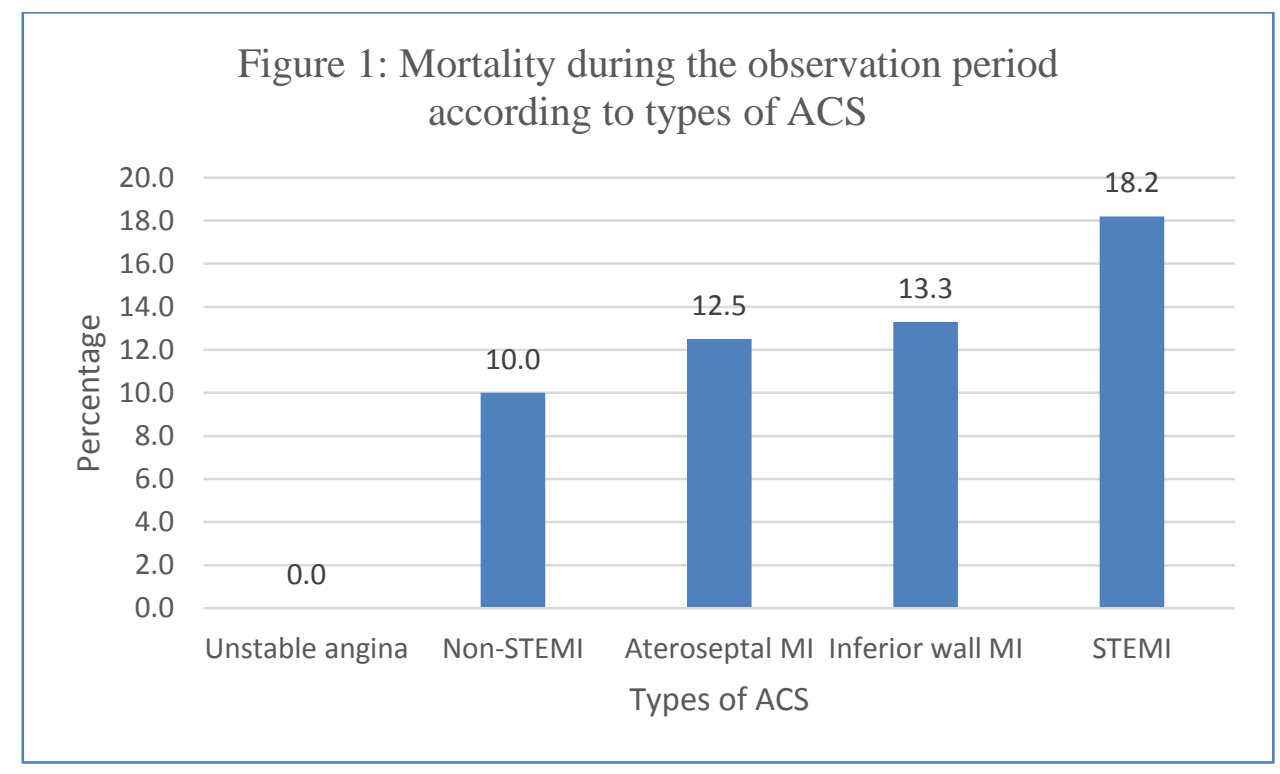


Figure 2: Kaplan-Meier's survival analysis based on intervention for reperfusion

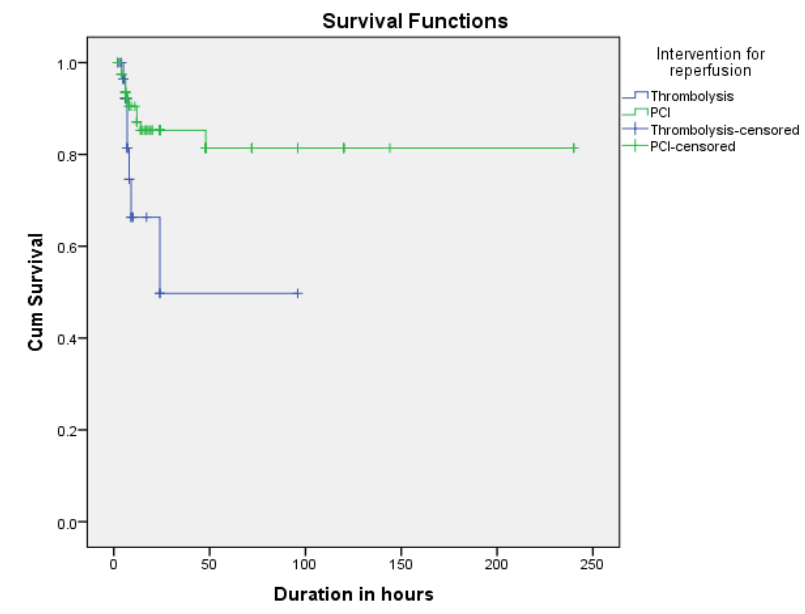

Log rank test $\mathrm{p}=.019$ Breslow $\mathrm{p}=.065$ Taron-Ware $\mathrm{p}=.037$

Figure 3: Kaplan-Meier's survival analysis according to BMI

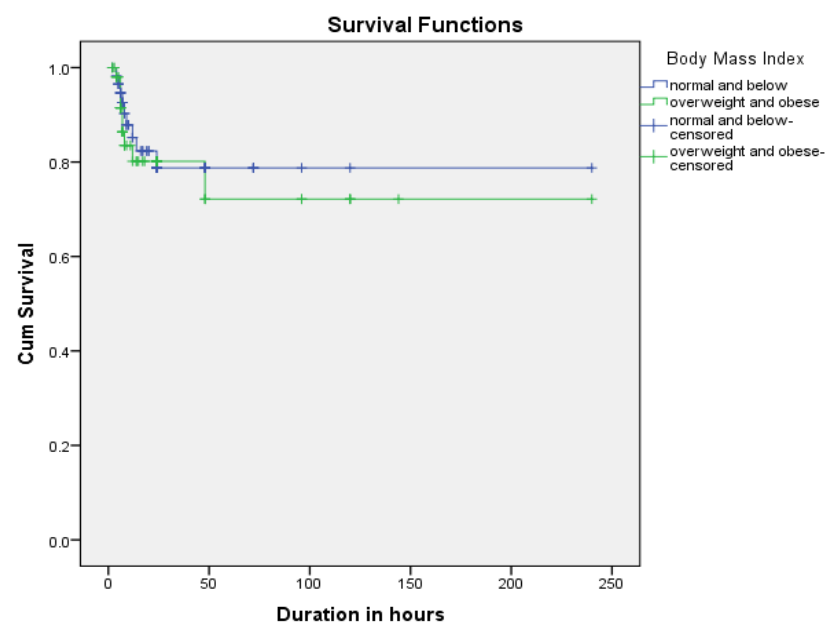

Log rank test $\mathrm{p}=.632$ Breslow $\mathrm{p}=.585$ Taron-Ware $\mathrm{p}=.613$

Figure 4: Kaplan-Meier's survival analysis according to abdominal obesity based on waist circumference

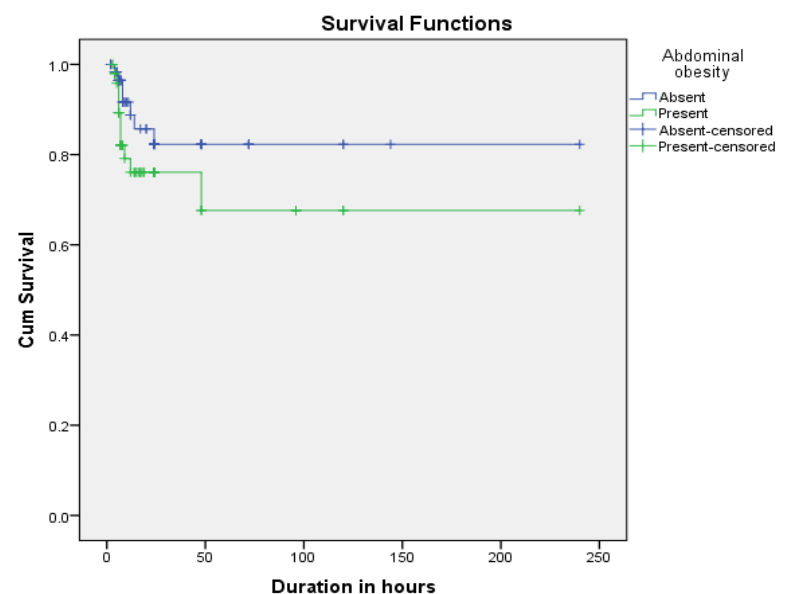

Log rank test $\mathrm{p}=.144$ Breslow $\mathrm{p}=.107$ Taron-Ware $\mathrm{p}=.123$
Figure 5: Kaplan-Meier's survival analysis according to presence or absence of obesity based on body fat percentage

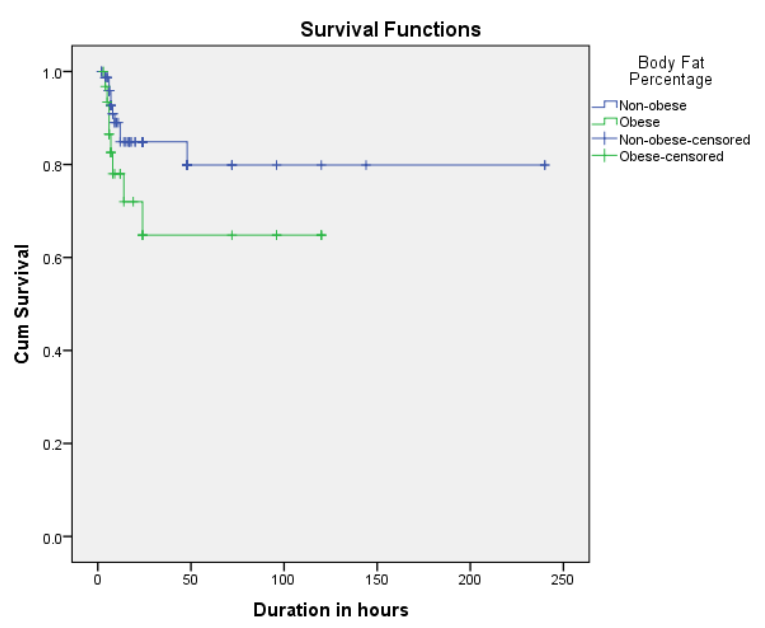

Log rank test $\mathrm{p}=.086$ Breslow $\mathrm{p}=.070$ Taron-Ware $\mathrm{p}=.073$

\section{Discussion}

The present study looked for the association of immediate outcome of ACS with types of reperfusion therapies (PCI, thrombolytic therapies) and obesity. It was found that BMI or body fat percentage or waist circumference (abdominal obesity) did not have any significant relationship with the survival of the patients during the observed period. Similar results were observed by Bakhoum et al. from Cairo, Egypt. (Gulf RACE-2 study, 2014) ${ }^{(31)}$ But, RomanoCorral et al. reported that overweight and obese CHD patients have a lower risk for total cardiovascular mortality compared with underweight and normal weight. CHD patients. (32,33) However, Romano-Corral et al. could not discriminate between Body fat and lean mass. This obesity paradox had also been shown in patients after Myocardial Infarction. Angerås et al. from Sweden also reported significant mortality among normal and underweight patients in comparison with moderately obese patients thus supporting the Obesity paradox.(based on SCAAR study). However, they have found that the association between BMI and mortality was U shaped with increasing risk in patients with morbid obesity. ${ }^{(34)}$ However, this has not dealt with Body Fat percentage or waist circumference (abdominal obesity) which are more indicative of 
visceral obesity. On the other hand, Dagenais et el in their report of Heart Outcomes Prevention Evaluation (HOPE) study concluded that "Obesity particularly abdominal adiposity significantly worsens the prognosis of CVD." (35)

\section{Limitation}

The present study has its own limitation. First, it was done for a short interval of a period of only 10 days of hospital stay. Long-term follow up could not be done due to lack of proper information retrieval system and follow-up.

\section{Conclusion}

It could be concluded from the present study, that obesity or overweight has no significant association with the mortality in the immediate period following acute coronary syndrome. Rather PCI intervention is the one which significantly increased the chance of survival during this period.

The authors would like to recommend large multicentric studies with longer period of follow-up.

\section{References:}

1. Cardiovascular diseases (CVDs) [Internet]. World Health Organization. 2018 [cited $29^{\text {th }}$ Nov 2018]. Available from: http://www.who.int/cardiovascular_diseas es/en/

2. Gupta R, Mohan I, Narula J. Trends in Coronary Heart Disease Epidemiology in India. Annals of Global Health. 2016; 82(2):307.

3. Prabhakaran D, Jeemon P, Roy A. Cardiovascular Diseases in India. Circulation. 2016;133(16):1605-20.

4. World Health Organization. (2000) Obesity: Preventing and Managing the Global Epidemic. World Health Organization Geneva, Switzerland.

5. Kopelman, P. G. (2000) Obesity as a medical problem. Nature. 404: 635-43.

6. Seidell, J. C., Flegal, K. M. (1997) Assessing obesity: classification and epidemiology. Br Med Bull.53: 23852.

7. Expert Panel on the Identification Evaluation and Treatment of Overweight in Adults (1998) Clinical guidelines on the identification, evaluation, and treatment of overweight and obesity in adults: executive summary. Expert Panel on the Identification, Evaluation, and Treatment of Overweight in Adults. Am J Clin Nutr. 68: 899-9

8. Kumar A, Cannon CP. Acute Coronary Syndromes: Diagnosis and Management, Part I. Mayo Clinic Proceedings. 2009;84(10):917-38.

9. Lavie C, Milani R, Ventura H. Obesity and Cardiovascular Disease. Journal of the American College of Cardiology. 2009;53(21):1925-32.

10. Patel N, Elsaid O, Shenoy A, Sharma A, McFarlane S. Obesity paradox in patients undergoing coronary intervention: A review. World Journal of Cardiology. 2017;9(9):731-736.

11. Smith, C., Dixon, R., Wynne, A., Theodorou, L., Ong, S., Subrayan, S., Davidson, S., Hausenloy, D. and Yellon, D. (2010). Leptin-induced cardioprotection involves JAK/STAT signaling that may be linked to the mitochondrial permeability transition pore. American Journal of Physiology-Heart and Circulatory Physiology, 299(4), pp.H1265-H1270.

12. Shibata R, Kondo K, Ouchi N, Walsh K, Murohara T. Impact of a Single Intracoronary Administration of Adiponectin on Myocardial Ischemia/ Reperfusion Injury in Pig Model. Journal of Cardiac Failure. 2009;15(7).

13. Tao L, Gao E, Jiao X, Yuan Y, Li S, Christopher $\mathrm{T}$ et al. Adiponectin Cardioprotection After Myocardial Ischemia/Reperfusion Involves the Reduction of Oxidative/Nitrative Stress. Circulation. 2007;115(11):1408-16. 
14. Gao J, Chang Chua C, Chen Z, Wang H, $\mathrm{Xu} \mathrm{X}, \mathrm{C}$. Hamdy $\mathrm{R}$ et al. Resistin, an adipocytokine, offers protection against acute myocardial infarction. Journal of Molecular and Cellular Cardiology. 2007;43(5):601-609.

15. Shibata R, Sato K, Pimentel D, Takemura Y, Kihara S, Ohashi K et al. Adiponectin protects against myocardial ischemiareperfusion injury through AMPK- and COX-2-dependent mechanisms. Nature Medicine. 2005;11(10):1096-1103.

16. Shibata R, Ouchi N, Ito M, Kihara S, Shiojima I, Pimentel D et al. Adiponectinmediated modulation of hypertrophic signals in the heart. Nature Medicine. 2004;10(12):1384-1389.

17. Smith C, Mocanu M, Davidson S, Wynne A, Simpkin J, Yellon D. Leptin, the obesity-associated hormone, exhibits direct cardioprotective effects. British Journal of Pharmacology. 2006;149(1):513.

18. Gorodezky C. Genetic Difference between Europeans and Indians: Tissue and Blood Types. Allergy and Asthma Proceedings. 1992;13(5):243-50.

19. Misra A. Ethnic-Specific Criteria for Classification of Body Mass Index: A Perspective for Asian Indians and American Diabetes Association Position Statement. Diabetes Technology \& Therapeutics. 2015;17(9):667-671.

20. Singh S, Sikri G, Garg M. Body Mass Index and Obesity: Tailoring "cut-off" for an Asian Indian Male Population. Medical Journal Armed Forces India. 2008;64(4):350-353.

21. Nuttall F. Body Mass Index. Nutrition Today. 2015;50(3):117-28.

22. Jackson AS, Pollock ML. Practical assessment of body composition. The Physician and Sportsmedicine. 1985 May 1;13(5):76-90.
23. Durnin JV, Womersley JV. Body fat assessed from total body density and its estimation from skinfold thickness: measurements on 481 men and women aged from 16 to 72 years. British journal of nutrition. $1974 \mathrm{Jul} ; 32(1)$ :77-97.

24. Siri WE. The gross composition of the body. Adv Biol Med Phys. 1956 Jan 1;4(239-279):513.

25. Kumar A, Cannon CP. Acute coronary syndromes: diagnosis and management, part II. In Mayo Clinic Proceedings 2009 Nov 1 (Vol. 84, No. 11, pp. 1021-1036). Elsevier.

26. Antman EM. ST- Elevation Myocardial Infarction. The AHA guidelines and scientific statements handbook. 2008 Dec 12:46-90.

27. Anderson JL, Adams CD, Antman EM, Bridges CR, Califf RM, Casey DE, Chavey WE, Fesmire FM, Hochman JS, Levin TN, Lincoff AM. ACC/AHA 2007 guidelines for the management of patients with unstable angina/non-ST-elevation myocardial infarction: a report of the American College of Cardiology/ American Heart Association Task Force on Practice Guidelines (Writing Committee to Revise the 2002 Guidelines for the Management of Patients With Unstable Angina/Non-ST-Elevation Myocardial Infarction) developed in collaboration with the American College of Emergency Physicians, the Society for Cardiovascular Angiography and Interventions, and .... Journal of the American College of Cardiology. 2007 Aug 14;50(7):e1-57.

28. Ulijaszek S. Obesity: Preventing and Managing the Global Epidemic. Report of a WHO Consultation. WHO Technical Report Series 894. Pp. 252. (World Health Organization, Geneva, 2000.) SFr 56.00, ISBN 92-4-120894-5, paperback. Journal of Biosocial Science. 2003; 35(4):624-25. 
29. Nutrition [Internet]. World Health Organization. 2018 [cited 28 October 2018]. Available from: http://www.who.int/nutrition/en/

30. Muth N. What are the guidelines for percentage of body fat loss? [Internet]. Acefitness.org. 2018 [cited 31 October 2018]. Available from: https://www.acefitness.org/education-andresources/lifestyle/blog/112/what-are-theguidelines-for-percentage-of-body-fat-loss

31. Bakhoum, S., Sorour, S., Elramly, M., Raslan, H. and Salama, I. (2015). Impact of waist circumference on hospital outcome and coronary angiographic findings of patients with acute ST-segment elevation myocardial infarction. The Egyptian Heart Journal, 67(2), pp.159165.

32. Romero-Corral A, Montori V, Somers V, Korinek J, Thomas R, Allison T, et al. (2006). Association of bodyweight with total mortality and with cardiovascular events in coronary artery disease: a systematic review of cohort studies. The Lancet 2006; 368 (9536): 666 - 78.

33. McAuley P, Myers J, Abella J, Froelicher V. Body mass, fitness and survival in veteran patients: another obesity paradox? Am J Med 2007; 120: 518 -24.

34. Angerås $\mathrm{O}$, Albertsson $\mathrm{P}$, Karason $\mathrm{K}$, Råmunddal $\mathrm{T}$, Matejka $\mathrm{G}$, James $\mathrm{S}$ et al. Evidence for obesity paradox in patients with acute coronary syndromes: a report from the Swedish Coronary Angiography and Angioplasty Registry. European Heart Journal. 2012;34(5):345-53.

35. Dagenais G, Yi Q, Mann J, Bosch J, Pogue J, Yusuf S. Prognostic impact of body weight and abdominal obesity in women and men with cardiovascular disease. American Heart Journal. 2005;149(1):5460. 